\title{
THE ROLE OF PUBLIC HEALTH OFFICERS IN PREPAREDNESS PLANNING AND MANAGEMENT OF HEALTH CRISES
}

\author{
R Strauss (reinhild.strauss@bmgfj.gv.at)1, R Muchl'11, M Kunze'2, H Hrabcik ${ }^{1}$ \\ 1. Bundesministerium für Gesundheit, Familie und Jugend (Federal Ministry for Health, Family and Youth), Vienna, Austria \\ 2. Medizinische Universität Wien, Zentrum für Public Health (Medical University Vienna, Centre for Public Health), Vienna, Austria
}

\begin{abstract}
The contribution of public health officers is of crucial importance in both the preparedness planning process and the response to health threats since the implementation of public health measures lies within the competence of the public health system. Thus, public health officers on regional and district level have to be involved in every stage of the planning process for crisis management. Federal structures of health systems as equivalent to the political structure of a country pose specific challenges for both the planning process and the response itself. The most important instrument for the evaluation of crisis plans, including the assessment of the public health officers' preparedness, is the performance of exercises. The success of a simulation exercise depends mainly on careful planning process, clear evaluation criteria and a work plan, that allows for necessary improvements of crisis plans of all involved organisations. Simulation exercises are an integrated element of preparedness activities on all administrative levels of the public health system. Depending on the nature of the exercise public health officers on regional and district level are involved as planners or as players.
\end{abstract}

\section{Crisis management planning}

\section{Specific experiences of Austria}

Austria has a federal political and administrative structure comprising nine federal states ("Länder") which represent the regional level. Regarding health issues, the Ministry of Health (Bundesministerium für Gesundheit, Familie und Jugend, henceforth $\mathrm{MoH}$ ) is responsible on the national level whereas the regional health boards hold responsibilities on the level of federal states. The autonomy of the federal states is guaranteed in the Austrian constitution. Generally, crisis management is not centralised but lies within the domain of the federal states, however, there is a political mechanism called "mittelbare Bundesverwaltung" (indirect federal administration), which allocates responsibility in certain health-related areas, including infectious disease control, to the national level [1]. This political mechanism is of relevance in crisis preparedness planning since the relevant authorities at the national level can ask the respective federal states to prepare for health threats in an adequate manner. Usually, preparedness planning concerning infectious diseases is done in a coordinated way by the regional and national public health bodies. One example is the common purchase of stocks of necessary medicines and medicinal products for crisis situations.

To overcome any potentially conflicting crisis management concepts on national and regional levels, the $\mathrm{MoH}$ usually implements the following planning process:
- on the national level, strategic framework crisis plans following international standards for different scenarios (e.g. smallpox, anthrax, influenza pandemic) are developed [2-7];

- all heads of the regional health boards and the medical universities are invited to actively participate in the writing and evaluation of crisis plans;

- the final strategic framework plans are then made available to the regional health boards to provide basis for the development of regional operative plans;

- the strategic plans are regularly updated by the $\mathrm{MoH}$ and sent for evaluation to the regional health boards and the scientific community.

This procedure of crisis management planning in the field of public health has proved to be very successful. To date, specific plans for smallpox, anthrax and influenza pandemic have been developed [8-10]. The major advantage of this planning strategy is that the regional public health boards that are responsible for the implementation of the crisis management plans are involved in the discussion of the proposed measures at the earliest stage of their planning.

\section{Simulation exercises}

\section{General principles}

The most important instrument used in the evaluation of crisis management plans is the performance of simulation exercises. To ensure that the exercise is successful, it needs to be carefully planned:

- Firstly, the aim and the type of exercise have to be determined. Different types of exercises are available and the choice should be done according to the aims: tabletop exercises are useful for testing procedures whereas command post exercises are optimal for testing communication. Drills and internal exercises are the most appropriate methods for testing operations.

- Secondly, the scenario has to be realistic and relevant for all the players but also rich enough to push the system tested to the limits. Clear objectives have to be defined and the timeframe has to be sufficient to allow for constructive response. It needs to be decided whether to use real time or compressed time: compressed-time scenarios allow for exercises that cover weeks or months whereas real-time scenarios are better to test operational issues.

- Thirdly, clear evaluation criteria have to be set up. Ideally, the evaluation process is supported by (external) observers. After the exercise, a specific working program has to be developed, including a road map allocating tasks to working groups. The 
results of the working groups have to be incorporated into the crisis management plans and follow-up exercises should be performed in order to evaluate the improvements. However, exercises must be spaced out appropriately and contain only a few repetition elements, otherwise the compliance of players might decrease with negative consequences affecting the quality of the performance. In fact, scenarios should be planned with a long term vision to ensure the best output. At the beginning, an internal exercise to test internal procedures and operations should be done. Then partners and stakeholders should be involved in a table top exercise to test the external procedures. Once these procedures are optimised, a command post exercise to test the communication between the parties involved should be performed.

Simulation exercises have to be performed on national, regional and district level. Depending on which administrative level the exercise is performed at, the role of the public health officers is different: in a national exercise the public health officers of the regional and district levels act as players, in a regional exercise which is planned by the public health officers working in the regional health board the district public health officers act as players, and, finally, in a district level exercise the district public health officer are the planners while the players are located in the different health care facilities.

International exercises NEW WATCHMAN and COMMON GROUND In 2005, the European Commission initiated two international simulation exercises - the smallpox exercise NEW WATCHMAN in October and the influenza pandemic exercise COMMON GROUND in November $[11,12]$.

Nearly all EU Member States as well as Switzerland, Iceland and Norway, the European Commission, the European Agency for the Evaluation of Medicinal Products (EMEA), the European Centre for Disease Prevention and Control (ECDC), the European Vaccine Manufacturers (EVM), several pharmaceutical companies and the World Health Organization (WHO) participated in these exercises. The UK Health Protection Agency (HPA) acted as exercise control and was supported by a Canadian consultant company which had a long lasting experience in doing this kind of exercises especially in the military field.

The main aims of the exercises were to evaluate:

- the communication between and within the relevant authorities in the EU Member States and at the EU level;

- the interoperability of the national plans;

- the division of tasks and responsibilities between the international organisations (EC, WHO, ECDC). The exercises were run as a command control exercise: each participating organisation had to name the controllers and players. The controllers' function was to monitor the flow of the exercise on site. Therefore these persons were involved in the preparation of the exercise at the EU level. In case of unforeseen difficulties it was the task of the controllers to step in and to bring the exercise back on track. The players had to react to the given events and solve the problems as quickly and effectively as possible.

Even though in these communication exercises no active role was foreseen for public health officers, the regional health boards were able to follow the exercises, because the controllers in the $\mathrm{MoH}$ forwarded them all the information. This was done in preparation of a national influenza pandemic exercise. Furthermore, several topics that needed further discussion on the national level were identified.

\section{National influenza pandemic exercise VAN SWIETEN}

VAN SWIETEN was the first Austrian national exercise to evaluate the crisis management of a national emergency due to an infectious disease $[13,14]$. In general, the EU exercise COMMON GROUND was used as a model in designing the scenario, aims and objectives of the national exercise, and it was further developed by taking into consideration the results of the evaluation of COMMON GROUND. The aim of the exercise was to evaluate the communication and the cooperation between the national and the regional level institutions during a pandemic situation. In contrast to the EU exercises, it was a staff exercise with controllers only being present at the national level. All public health officers at the regional level were actively involved while the involvement of the district level personnel was voluntary.

The main objectives of the exercise were to evaluate:

- the communication between the $\mathrm{MoH}$ and the nine regional health boards as well as the other involved ministries;

- the general preparedness plan for an influenza pandemic in Austria;

- the interoperability of the regional plans.

The most important elements of the exercise were therefore:

- surveillance during a pandemic;

- preventive and control measures such as the use of antiviral drugs and the pandemic vaccine;

- logistic issues;

- cross-border issues, such as "health shopping" and travel restrictions.

The scenario of this two-day-long exercise was divided into three blocks and covered in real time several months (November 2006 to April 2007). Each block was played in compressed time. In block 1 (morning of exercise day 1 , representing 23 November, 2006), players had to react according to pandemic phase 5 to a situation in which clusters of human infections with a new influenza virus subtype appeared in South-East Asia. In block 2 (afternoon of exercise day 1 , representing the period between 24 November and 20 December, 2006), players had to manage pandemic phase 6 with no availability of pandemic vaccine. In block 3 (exercise day 2 , representing the period between 21 December, 2006 and 12 April, 2007) the logistics for the use of the pandemic vaccine during the second pandemic wave (phase 6) had to be handled.

VAN SWIETEN was evaluated by the same methods as used in the evaluation of COMMON GROUND [12]. The evaluation process revealed the need for intensive work in several areas:

- continuous interministerial cooperation concerning the issue of border control and/or closure of borders, closure of airports and "health shopping";

- specific plans for business continuity;

- planning presumptions (definition of triggers for certain measures such as closing schools or release of neuraminidase prophylaxis for frontline personnel).

However, one of the most important conclusions of the evaluation process was the need for strengthening the public health sector. A well functioning public health system is the backbone of successful crisis management in the field of infectious diseases and thus 
needs to be supported concerning human and financial resources. Furthermore, public health officers need to have a continuous access to training on high level. Therefore in 2006, the Austrian $\mathrm{MoH}$ started a special initiative to send key personnel of the regional health boards to international training seminars and workshops [15]. In this way, a group of well trained public health experts will be established who can function as multipliers on regional level by training the local staff. Additionally, the $\mathrm{MoH}$ organises crisis management training seminars on national level.

\section{Conclusion}

Public health officers on all administrative levels play a crucial role in crisis planning and in the management of crisis situations. Thus the public health sector has to be involved in every crisis management planning process in order to implement all operative issues right from the start. The roles and competencies of the different administrative levels have to be clearly defined in practical terms and the functionality of the standardised operational procedures has to be tested repeatedly in exercises.

Public health officers have different roles in preparedness planning and crisis management depending on the administrative level they are working at: while a public health officer at the district level is mainly involved in operational issues, a public health officer at the regional level is responsible for coordinative and strategic measures within the federal state. Thus their involvement has to be implemented accordingly: operational training such as delivery of neuraminidase inhibitors or vaccine is addressed at the district level while strategic training such as planning hospital care throughout the federal state is addressed at the regional level.

Exercises are the most important tool to evaluate crisis plans and thus the level of preparedness among public health officers. In order to design scenarios that are as realistic as possible, public health officers on all administrative levels have to be involved already in the exercise preparation. By this it is guaranteed that all relevant issues are included in order to improve the performance in case of a real crisis.

\section{References}

1. Weber K. Die mittelbare Bundesverwaltung. Schriftenreihe des Instituts für Föderalismusforschung Band 41. Wien: Braumüller; 1987.

2. WHO. WHO Global Preparedness Plan 2005. Available from: http://www.who. int/csr/resources/publications/influenza/WHO_CDS_CSR_GIP_2005_5/en/index. html

3. Department of Health, UK. Guidelines for smallpox response and management in the post-eradication era (smallpox plan). Available from: http://www.dh.gov. uk/en/Publicationsandstatistics/Publications/PublicationsPolicyAndGuidance/ DH_4070830

4. Henning KJ, Brennan PJ, Hoegg C, O'Rourke E, Dyer BD, Grace TL. Health system preparedness for bioterrorism: bringing the tabletop to the hospital. Infect Control Hosp Epidemiol. 2004;25(2):146-55.

5. Barbera J, Macintyre A, Gostin L, Inglesby T, O'Toole T, De Atley C, et al. Large-scale quarantine following terrorism in the United States: scientific examination, logistic and legal limits, and possible consequences. JAMA. 2001;286(21):2711-7.

6. CDC. Bioterrorism Preparedness and anthrax. Available from: http://www.epi. state.nc.us/epi/anthrax.html

7. Tomaso H, Al Dahouk S, Fock RRE, Treu TM, Schlögel R, Strauss R, et al. Management in der Behandlung von Patienten nach Einsatz biologischer Agenzien. Notfall \& Rettungsmedizin. 2003;6:603-14

8. Strauss R. Influenza Pandemieplan - Strategie für Österreich. Available from: http://www.bmgfj.gv.at/cms/site/attachments/3/6/8/CH0019/CMS1126084167391/ pp_inetversion12_06.pdf
9. Reisp E. Krisenplan Aviäre Influenza und Newcastle Disease. Available from: http://www.bmgfj.gv.at/cms/site/attachments/3/6/8/CH0019/CMS1126084167391/ kp_ai_ncd.pdf

10. Strauss R. Der österreichische Pockenplan. Available from: http://www. arztenews.at

11. European Commission. NEW WATCHMAN - Final exercise report. Available from: http://ec.europa.eu/health/ph_threats/com/watchman.pdf

12. European Commission. COMMON GROUND - Final exercise report. Available from: http://ec.europa.eu/health/ph_threats/com/common.pdf

13. Strauss R, Muchl R, Kunze M, Hrabcik H. Simulationsübungen - ein integraler Bestandteil umfassender Pandemieplanung. Available from: http://www. verwaltung.steiermark.at/cms/dokumente/10039771_21212/dc944064/ Jahresbericht2006Endversion.pdf

14. Strauss R, Muchl R, Hain C, Kunze M, Hrabcik H. VAN SWIETEN - Erste österreichweite Pandemieübung. Mitt Sanit Verwalt. 2007;108(7):2-3.

15. Strauss R, Karnthaler U, Gössler R, Morawetz R, Van Loock F, Baka A, et al. ETHREAT - European Training for Health Professionals on Rapid Response to Health Threats. Mitt Sanit Verwalt. 2007;108(7):3-5.

This article was published on 13 March 2008.

Citation style for this article: Strauss R, Muchl R, Kunze M, Hrabcik H. The role of public health officers in preparedness planning and management of health crises. Euro Surveill. 2008;13(11):pii=8071. Available online: http://www eurosurveillance crises. ViewArticle.aspx?ArticleId $=8071$ 